\title{
E-CONTACT TRACING OF HOSPITAL INFECTIONS - VALIDATION OF SIRSZ AUTOMATIC RISK ASSESSMENT
}

\author{
ANDRZEJ JARYNOWSKI \\ Interdisciplinary Research Institute \\ ul. Oriona 15/8, 67-200 Głogów, Poland \\ e-mail address: ajarynowski@gmail.com \\ ORCID: 0000-0003-0949-6674 \\ IRENEUSZ SKAWINA \\ University of Social Sciences \\ M. Kozara-Słobódzkiego 21, 58-105 Świdnica, Poland \\ Interdisciplinary Research Institute \\ Oriona 15/8, 67-200 Głogów, Poland \\ e-mail address: iskawina@san.edu.pl \\ ORCID: 0000-0001-6614-5649
}

\begin{abstract}
Aim. Contact networks play a crucial role in infectious disease propagation and position in the network mediate risk of acquiring or sending infections. We studied the spread of hospital-associated infections through computer simulations and validated our 'computer assisted' risk assessment with 'human' risk assessment in a prospective study.

Concept. We collected time-varying structure of contacts and covariates reconstructed from Polish Hospitals:1. The organisational structure is mapped by a set of questionnaires, CAD maps integration, functional paths annotation and local vision. It is done mostly by surveys within medical staff through an interactive web application. 2. The Cohabitation layer processes data from the registry of patient admissions and discharges from each hospital unit (wards, clinics, etc.) and medical shift register. With simulated infection paths, we were able to compute network centrality measures for patients. We obtained the risk of getting infected, based on the patient's incoming connections, and the risk of spreading infections resulting from outgoing connections. We compare various standard centrality measures - position of patients and staff in contact networks ('computer assisted' risk assessment) of both contacts and paths networks, with a predictor of 'human' risk perception (based on 190 patients).

Results. We showed that the best predictor of HAI risk is Adjusted Rage Rank on paths ( $r$ $=0.42, \mathrm{p}<0.01)$. However, surprisingly good predictive power in risk assessment was found in the betweenness centrality of the underlying network of contacts $(r=0.30, p<0.01)$.

Conclusion: We conclude that epidemiology of a given pathogen in a given place and time could be explained only with the contact network only to a large extent. However, further possibility of the collection, processing and storage of the data on individual persons,
\end{abstract}


translated to mathematical modelling could lead in future to satisfactory improvement in risk assessment.

Keywords: e-health, hospital infections, tele-medine, epidemiological modelling, support decision system, epidemiological intelligence

\section{INTRODUCTION}

We want to present a hospital infection risk assessment system, which is a part of a bigger SIRSZ 'System Informatyczny Redukcji Szpitalnych Zakazen' project (www.sirsz.pl) trying to increase the understanding of how pathogens are transmitted in Polish hospitals by epidemiological modelling (Jarynowski, Marchewka, \& Grabowski, 2017). Human health and life is the most precious gift. However, data needed for our models usually already exists in Polish hospital/organisations/insurance/public health authorities databases, but rarely has been modelled (up to our knowledge) from epidemiological intelligence perspective (Jarynowski, Grabowski, 2019). The spread of the SARS-CoV-2 virus has made infectious disease modelling, in its broadest sense, a useful tool among researchers and IT communities. The current COVID-19 pandemic makes not only modelling techniques very popular, but so many representatives of the medical community are more and more familiar with the crucial concepts of risk assessment and estimations of probabilities of infections. Thus, development of new procedures for dealing with COVID-19 outbreaks of other infectious diseases through the use of contact tracing tools and social network analysis has speeded up recently (Ahmed et al., 2020).

\section{HOSPITAL INFECTION AND INFECTION CONTROL}

Hospital infections (called also nosocomial infections, hospital acquired infections, healthcare associated infections) are the most common adverse events in Polish healthcare (Wojkowska-Mach et al., 2016). Of the 4 million patients who go to Polish hospitals every year, 5-15\% of the patients (Cassini et al., 2016; Seweryn, 2018) acquire infections (between 200 and 600 thousand) and it costs more than 800 milion PLN due to subsequent treatment and compensation paid to infected patients. Polish hospitals are obligated both by national and European legal standards to prevent and control hospital infections. Hospital pathogens (mainly bacteria) may also acquire antibiotics resistance (Rodríguez-Rojas et al., 2014). The scale of the problem can be illustrated by projections that in the next 30 years more people would die due to antibiotic resistance than cancer ( $\left.\mathrm{O}^{\prime} \mathrm{Neill}, 2016\right)$. In Polish hospitals, the prevention of nosocomial infections is mainly based on proper hygiene (standard isolation) and passive surveillance, but there are no tools available to identify sources and predict most likely infection paths (Wasilewski, 2018). On the other hand, most of Polish hospitals adopted ubiquitous IT solutions and complex business intelligence models for administration and economical purposes (Jarynowski \& Grabowski, 2019). 
Epidemiology of hospital infections differs not only between pathogens, but also for example between clinic types (Donker, Wallinga \& Grundmann, 2010). Transmission can not only occur directly via human-human contacts, but also come from environment or medical instruments (de Bruin, Seeling \& Schuh, 2014). Immunocompetency of a patient can also play a role, while a patient with some condition can be a non symptomatic carrier/colonised (Piszczek et al., 2014; Rocha et al., 2020) or sometimes pathogens can cause deadly diseases such as Sepsis.

We trained our software to work with few pathogens (MRSA, Influenza, Clostridium Difficile, Acinetobacter Baumani, Klebsiella Pneumoniae NDM), but we use methicillin-resistant Staphylococcus aureus (MRSA) as a model organism, because: it is mostly related to hand transmission; it is largely restricted to health care institutions (at least in Europe); and finally, MRSA evolves clonally (Donker, Wallinga \& Grundmann, 2010). The MRSA is resistant to more than half of all antibiotics and it was known to be the single largest care-related infection problem (Stenhem, 2006) for many years. For such infectious diseases, in which close contact is needed for the transmission to occur, an individual's position in the contact network is important for that person's risk of getting infected (Liljeros, Giesecke \& Holme, 2007).

\section{AIM OF SYSTEM DEVELOPMENT AND PROSPECTIVE OBSERVATIONAL STUDY}

We propose an electronic system of hospital infections risk assessment (free of charge, open licensed) for local use in hospitals. The primary version of the software is in Polish, but it has an English branch. Pilot implementation was done in a few Polish hospitals, where in two of them our software was validated in prospective observational study.

The aim of the presented tool is to extract infection paths within multilayer networks in hospitals on our own example of risk assessment implementation. Backward contact tracing is a key method (ECDC, 2020) for understanding transmission chains (COVID-19 showed how important it is). Digital tools can play a role in enhancing forward (as we proposed in this tool) contact tracing activities (WHO, 2020). Methods to analyse the contact network of persons visiting the same hospital ward have already been applied (Jarynowski \& Liljeros, 2015). However, understanding in which way all layers (Fig. 1) organisational (Ueno \& Masuda, 2008), spatial (Teixeira et al., 2015) and of course empirical network structure affects the transmission of infections were still missing. We have investigated some of blind spots, because previous approaches have been homogeneous in terms of methodology used. We clarified possibilities to extend the computational model of disease spread as a freely available tool via incorporation of the detailed contact structure on intra-hospital level as obtained from Polish hospitals via surveys and co-location analysis. 


\section{NETWORKS, MODELLING AND HOSPITAL INFECTIONS}

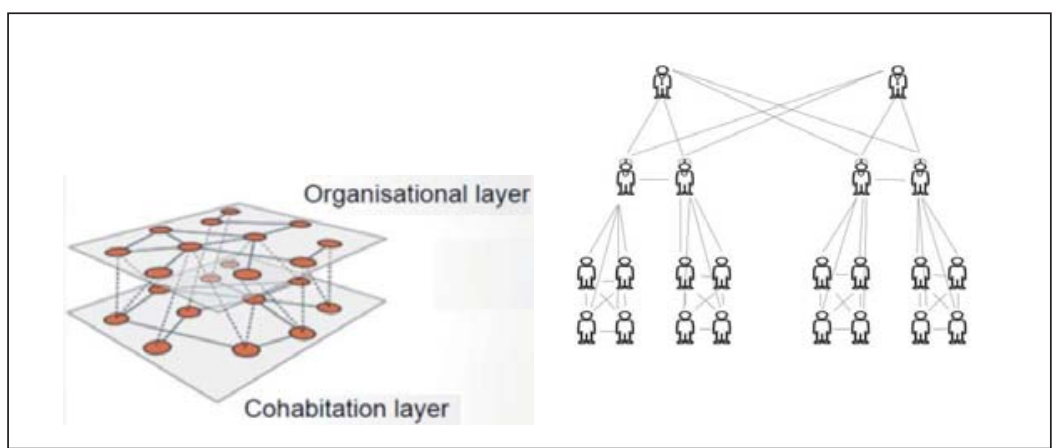

Fig. 1. Structure of hospital interactions implemented in our System, where node is a given person (patient, staff) and link is a contact [left] Multilayer approach combining cohabitation layer with organisational layer of the network [right] Illustrative diagram representing possible hierarchical organisational structure in hospital.

Source: Own elaboration

Health care institutions are associated with many hospital-specific pathogens such as opportunistic bacteria. The awareness of the importance of contact networks has brought methods from sociological studies of social networks into the area of preventive infectious disease protection work and exploded due do COVID-19 pandemic (Jarynowski, 2014; Tahir et al., 2021). The contact patterns and network structures observed in the general population are also present in hospitalised patients and thus influence the propagation of hospital-associated pathogens. Close proximity interactions can be also measured by electronic sensors (Vanhems et al., 2017) are increasingly used to inform contact networks. By analysing the disease transmission in hospital populations from studies using sensors (eg. beacons) for contact identification, we can receive prior weights of our networks (Obadia et al., 2015). Comparing data collected in our study with sensoric ones (with much higher resolution), the full temporal portrait can be explored (Valdano et al., 2015). In our case, it is assumed that individuals only meet in hospitals. Moreover, Inter-hospital interactions can be also measured by referral networks and are increasingly used to inform contact networks (Belik et al., 2017). In other chapters of SIRSZ project, we analyse both intra and inter hospital transmissions (Jarynowski, Marchewka \& Grabowski, 2017), however in this paper we study the dynamics for each single hospital separately. Advantages in our analysis gained by treating the hospital as a closed system are obscured due to certain medical interventions and hospital policy to diagnosed HAI cases by quarantine, cohorting and other epidemiological intervention. We use ABM (agent based modeling) computational techniques used for experiments with artificial systems populated by agents that interact in non-trivial ways (Jarynowski, 2014). This is probably the most common current approach to modelling by infectious disease epidemiologists (Heslop et al., 2017). Additionally, SNA (social network 
analysis) serves as a methodology and set of tools enabling an exploration of interacting agents - healthcare system participants (Fig. 1).

\section{Decision Making Support System}

Recently, the knowledge of complex system tools for sociology and medicine such as networks has undergone an accelerating growth, however all models of such systems are incomplete without real data, especially register-based (Ohst et al., 2014). Epidemiological modelling can support outbreak responses (Heslop et al., 2017) and COVID-19 pandemic (Becker et al., 2021). Simulation is relevant only if reliable data whose parameters can be calibrated to run simulations (Grundmann \& Hellriegel, 2006). Prior parameters were adopted from literature review, but the requirement to calibrate the parameters for a given hospital can be satisfied only if infection control team, IT and administration of the hospital would cooperate with modellers (Eggo, Cauchemez \& Ferguson, 2011). The built model can not only describe the spread of pathogens, but the hospital team can gain experience in the innovative network perspective of analysing outbreaks not taughtu in Polish medical universities before COVID-19 pandemic. Computer assisted tools for hospital infections have already become part of clinical practices in many developed countries. However, there is still a lack of dynamic network models generating temporal networks of typical behaviour observed in real hospitals (Knight et al., 2019). It is already known that a computer-aided treatment planning of hospital infections can be more efficient and safer than "analog" with the involvement of the medical microbiologist (Leibovici, Kariv \& Paul, 2013). Our tool could be part of a bigger hospital intelligence system (Adlassnig et al., 2012) and by synergy would help in effective decision making by epidemiological surveillance and intelligence, outbreak response, as well as infections prevention and, ultimately mitigation .

\section{SYSTEM DESCRIPTION}

The hospital system consists of three modules: initialisation questionnaire, extended simulation environment and desktop application with simulation engine. We provide a user guide (http://platforma.sirsz.pl/course/view. php?id=7) and manual (http:/ / platforma.sirsz.pl/course/view.php?id=5) of the system in Polish. Our system allows us to collect and process locally time-varying structure of contacts reconstructed from patients' e-records and staff surveys (currently only Polish hospitals). Our organisational networks were built via selfreported data or direct observations on person-to-person interactions and functional mobility. Our cohabitation layer is the proximity, that people who were registered in the same place at the same time are linked.

Input data of our software (method of collection in brackets):

- DATA organisation: functional topology (manually);

- DATA cohabitation: patients visits (automatic);

- DATA organisation: staff shifts (half-automatic);

- DATA epidemiology: microbiological tests (semi-automatic). 
Output:

- risk assessment for patients (risk of acquiring infection and risk of infecting others);

- most likely paths of infections.

\section{INITIALISATION QUESTIONNAIRE}

In this part, we ask the infection control team in the hospital to complete the survey (English version: www.platforma.sirsz.pl/hospital2) and export data to .csv file to get started. Survey is available via the Internet (no information about patients is sent outside of the hospital) in Moodle technology (Fig. 2). The questionnaire consists of four groups of questions:

1. hospital organisation (all hospital buildings and floors, clinic/departments, etc.);

2. ward/department organisation (selected hospital departments participating in program as subdivision to wards, number of beds, average occupancy, ward type, percentage of transfers from other hospitals, location, patient rooms, other rooms, neighborhood structure of the rooms with nearest toilet location, etc.);

3. staff workflow (for nurses: where and how the nurses are working, for doctors: their time span in different wards, etc.);

4. invasive procedures and patient transport (list of invasive procedures, procedures places, frequency of realisations, etc.).

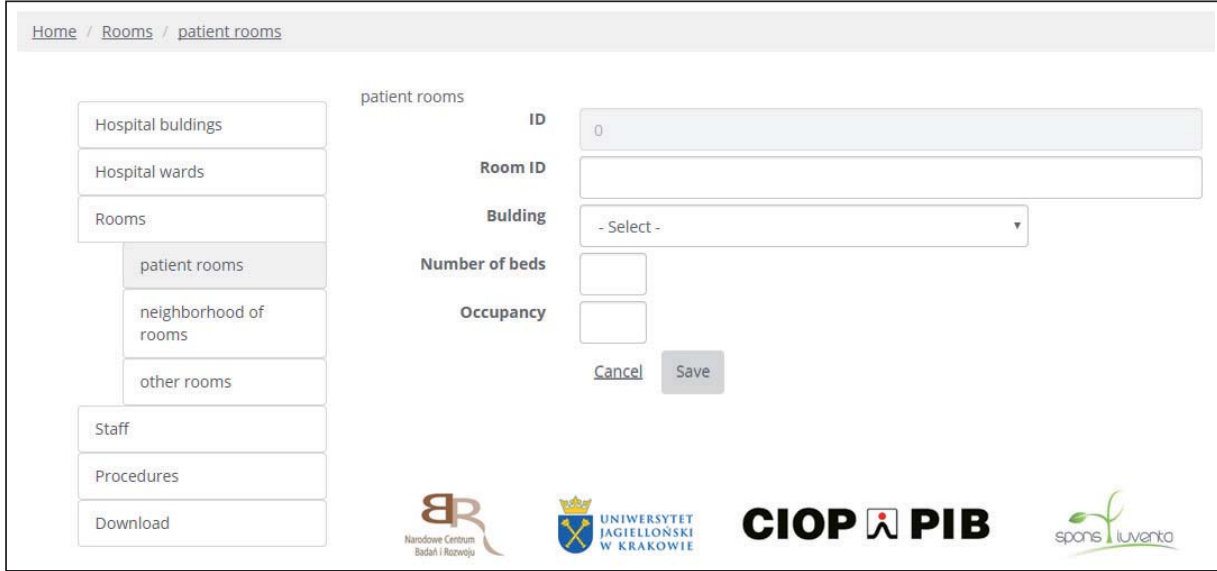

Fig. 2. Example of survey to fill out: patient room (room id, location, number of beds, occupancy)

Source: Own SIRSZ elaboration

In an effect of proper initialisation, we could also extract the social network of hospital staff (Mikołajczyk et al., 2008) from self-reporting diaries (Smieszek et al., 
2012). There is Polish and English tutorial of initialisation questionnaire (http:// platforma.sirsz.pl/course/view.php?id=9\#section-1).

\section{EXTENDED SIMULATION ENVIRONMENT}

The initiation results from the survey can be translated individually to the simulation environment. This is not a required component of implementation, but in this step the hospital provides the most information about its functionality. As all the procedures of the SIRSZ system are at least partially automatised, here an individualised process should be performed by the SIRSZ team on the basis of information obtained from the hospital. The main aim obtained by surveying is systemic understanding of the susceptibility of the healthcare setup (in current state or in any other possible states) to the occurrence of the outbreaks.

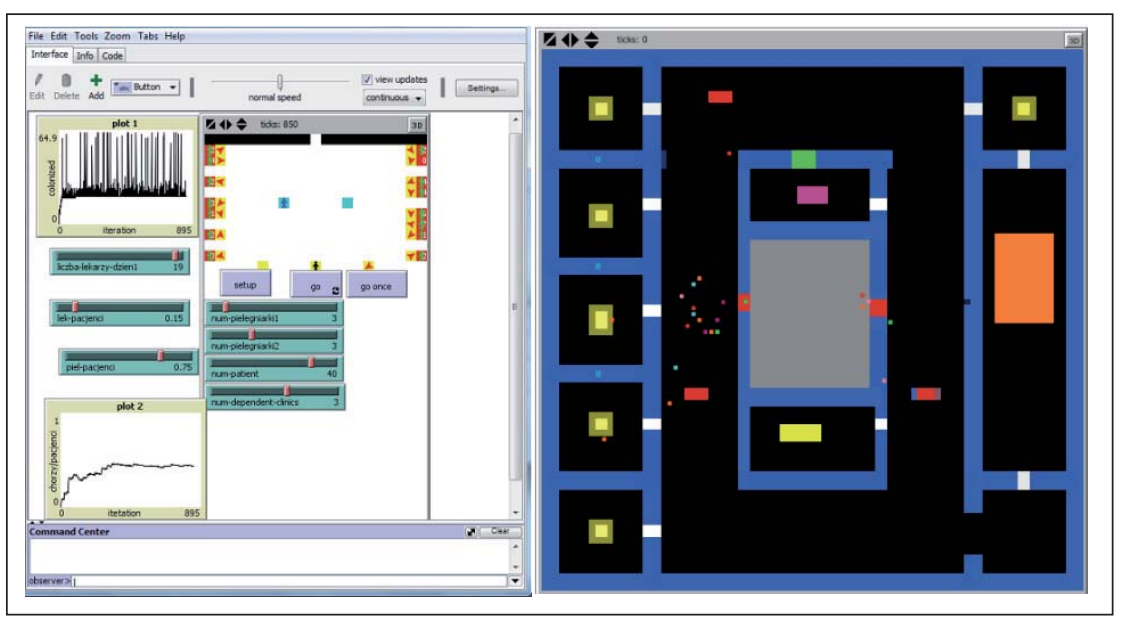

Fig. 3. Netlogo representation of our extended simulation environment implemented for a given clinic [left] Training environment for a given clinic with two ward at two floors of the building simplified using syntax theory of architecture [right] CAD adaptation of single ward with agents moving around it.

Source: Own research

We use free software Netlogo to build and run extended simulations. In the NetLogo programming language, the turtle is a representation of an agent (an autonomous, interacting entity). A patch is the elementary spatial unit in the NetLogo grid (element of the locations). The goal is to imitate real patterns by running (often computerised) an ABM under different interventions and conditions (Fig. 3). The main reason for using such a tool is its flexibility, and lso possibility to implement organisational habits not fitting to the frame of structuralised initialisation survey. We mainly model the movement of healthcare workers in the hospital topological semantic space (simplified version of metric spaces (Grabska, Łachwa \& 
Ślusarczyk, 2012)) according to surveys and local vision. Patients move along to a lesser extent (at least in the model), for example to the toilet. However, patients can be transported by staff to the procedure's room. Movement of hospital agents allows us to construct contact networks (Curtis et al., 2010), which will be much more detailed than these collected in core parts of our systems. The final aim is to integrate a wide range of networks in which physical contact is a crucial factor. Within the proposed extended framework, we also study possible scenarios of organisational change as dedicating staff to patients, transport paths rerouting, shift distributions, geo-localisation isolated/cohorted patients, etc (Jaramillo et al., 2015). Built model describes the possible spread of pathogens and could indicate an effective strategy in the fight against infectious diseases. That would help in effective decision making by epidemiological surveillance. However, proper implementation of such an environment is extremely time consuming for each hospital, so our templates are more educational tools, than Decision Making Support engines.

\section{DESKTOP APPLICATION}

The application collects data from the initialisation questionnaire, the hospital information system (HIS) and uses them to run calculations. Application interface is written in Visual Basic and the executive engine of simulation is written in R. At this point our system does not communicate with the Internet and all import/ export procedures operate on the Intranet only. It is possible to manually enter some data directly into the application.

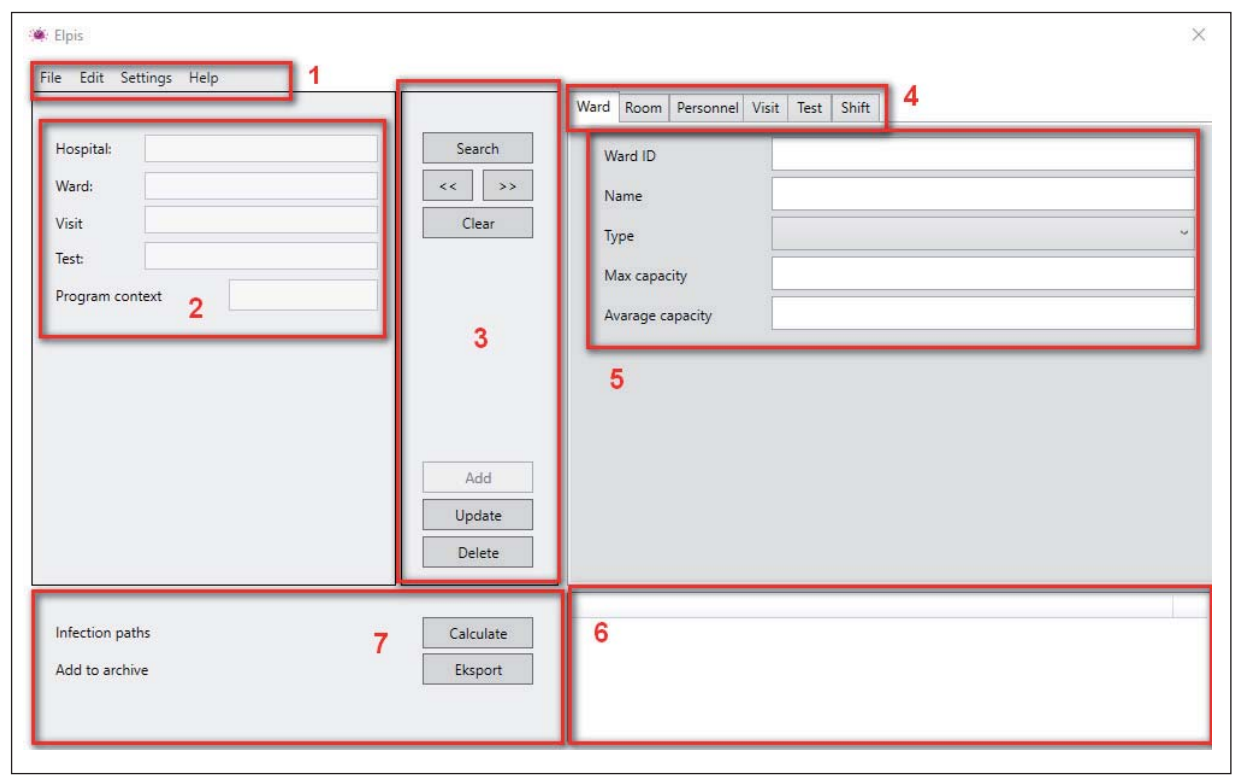

Fig. 4. Desktop Application Interface with marked functional fields Source: Own SIRSZ elaboration 
Graphical User Interface is divided into seven parts (Fig. 4):

1. Main menu 2. Preview filter search 3. Content Management Panel (search, add, and delete entries from the database) 4. Navigation menus for switching between different forms 5. Data entry form 6. Preview the contents of the application database. Presentation of search results. 7. Panel to run calculations and export data.

On the left of the program window, information about current browsing is displayed. In the middle part there is a user panel with buttons that allow viewing data and perform basic operations on them. On the right side of the window there are boxes showing the six main data types of information collected:

- ward (clinic or ward description imported from initialisation survey);

- room (room description imported from initialisation survey);

- personnel (staff obligations imported from initialisation survey);

- $\quad$ visit (patient visits imported from Hospital Information System);

- test (microbiological test results entered manual by user);

- $\quad$ shift (staff shift entered manually by user);

- patient (personalised hospitalisation history). This entity was not allowed to be edited by Personal Data Protection Officers in participating hospitals, but is available for non-Polish hospitals.

There is Polish and English tutorial of desktop application (http://platforma. sirsz.pl/course/view.php?id=9\#section-2).

The application generates the most likely path of spreading infections and classifies patients into different risk groups with use of the model described in the following chapter.

\section{Mathematical Model}

Predictive modelling is a rapidly developing area in hospital infections and COVID-19 speeds up this process (Donker et al., 2021). Already widely applied in predictive models of interventions such as screening patients, modelling is a key input to policy and planning decisions in hospital epidemiology. Understanding how trends in prevalence and incidence will unfold from the beginning of the outbreak helps infection control teams evaluate and prepare for future priorities. The focus of our system SIRSZ is on building predictive models of hospital infections on a network and on assessing the value of modelling results for hospital epidemiologists (which still does not exist in Polish law, but due to our voice in public consultation it could be improved (RPL, 2017)).

The core mathematical model of infection transmission is SIR (Jarynowski \& Grabowski, 2015), where patients population is divided into three classes: the susceptible (S), who can catch the disease; the infectious (I), who can transmit disease and have it; and the removed (R), who had the disease and have recovered (with immunity) or are isolated from hospital population. Staff is divided in two categories: the susceptible (S) and the infectious (I) but we understand such an infection 
as a colonisation, because personnel usually do not develop clinical symptoms of diseases for most of hospital infections, but could still transmit pathogens.

Other models of infection propagation as SI (Jarynowski \& Liljeros, 2015), Ising (Jarynowski \& Grabowski, 2018) or Rumor (Grabowski \& Jarynowski, 2016) have been also considered. Propagation simulation runs with a daily step on a weighted and temporal network of contacts between agents: patients, doctors and nurses. The contagion to a susceptible from infectious agent can occur scholastically if there is a link between them at a given time with probability proportional to weight. Weights correspond to mixing patterns between different levels of neighborhoods or different types of interactions. For example, a link between patients sharing the same room should be stronger than a link between patients in the same ward, but in other rooms. Moreover, the link between nurse and patient should be stronger than link between doctor and patient, because in general doctors have many patients and spend much less time with a single one with less invasive procedures than nurse (on average).

\section{FitTING PROCEDURE}

We must fit two sets of parameters: parameters of SIR propagation and contact weighting parameters. Weighting matrix (weights on contact between different types of agents at a different level of neighborhood) is imported from an extended imputation environment (if skipped, baseline matrix is built in software). To fit SIR propagation we have started with a priori possible parameter range from literature (Sadsad et al., 2013; Jarynowski \& Liljeros, 2015; Jaramillo et al., 2015; Rocha et al., 2020) as well as mixing coefficient matrix from extended simulation environment/baseline. Then we took historical outbreaks from our hospitals. We have run classical SIR model over possible range of parameters with defined penalty function which are based on (in order of importance):

- Penalty of omitting really infected agents;

- Penalty for wrong time of infections: sum over absolute difference between simulated and real infection time;

- Additional penalty for too long big or too short infection chains: normalised absolute difference between number of agents affected and number of simulated infections.

For fitting a single outbreak thousands of simulations were performed to minimise penalty function. As the function is highly nonlinear, we do not expect to find a global minimum of the penalty function. Instead, a shorter list of few local minima is obtained. Such a ranked list forms a discrete distribution of a posteriori parameters space with intensity corresponding to local penalty estimates. Such a fitting is very computationally costly, so it was not performed at a local computer in hospitals, but at a high performance computer cluster.

If no outbreak of a given disease was observed in hospital before or cohabitation/staff data was not available, then fitting procedure is skipped and a priori or manipulated 'by hand' parameters will be used in prospective simulations. 


\section{RETROSPECTIVE OUTBREAK INVESTIGATIONS}

With a given dataset and parameter set, a retrospective prediction can be performed. This is a case to learn how to use tools by explaining historical outbreaks. To do so, we move back in time to the beginning of an outbreak. We take one up to few first cases as sources of propagation. We run propagation of the pathogen and obtain simulation paths of infections. Our system registers all virtual transmission events (who infected who and when). Cumulative network of such transmission links is mapped on network, where agents are nodes and weighted links are proportional to number of virtual transmissions accrued on the link. We search for the most likely paths in such a network (usually there are many of them), by calculating the shortest path between sources and nodes (agents who could take part in transmission paths). We compare visually if computed paths are similar to those revealed in outbreak investigation. There is possibility to play with visual presentation of the simulating path by manipulating layout function (fruchtermanreingold method is implemented (Csardi \& Nepusz, 2006)) or cut-off threshold (minimal number of transmission events for a link to appear).

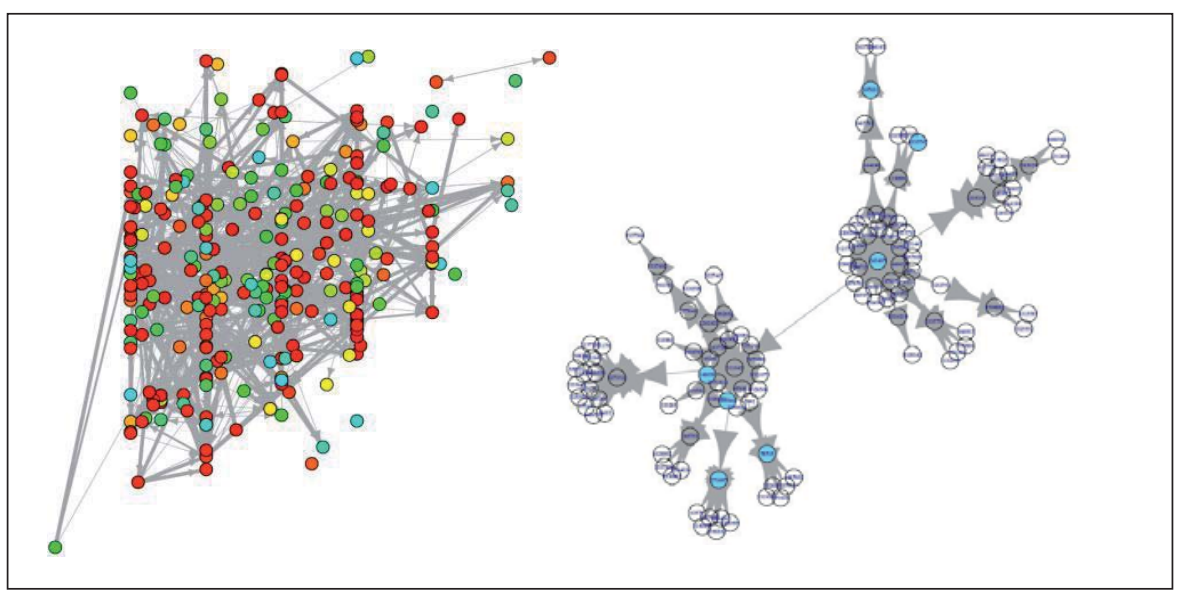

Fig. 5. Cumulative transmission paths of hospital infections [left] 281 infected cases in non-Polish hospital outbreak (only infected patients presented) [right] 8 infected cases in Polish hospital outbreak (all possible hospital agents - patients and personnel - presented with actually infected on color).

Source: Own research

Risk assessment is calculated based on node centrality (Landherr, Bettina \& Heidemann, 2010) calculation. We consider few centrality measures which take into account not only local, but also global importance of a given node (Paradowski et al., 2021). The first guess for risk in classical network's theory (Rustam, 2006) is betweenness centrality (number of shortest path passing nodes). For better description of in- centrality, Page Rank Algorithm was also implemented in our software. However, we are interested in both in- and out- centrality, where 
betweenness is neutral and Page Rank is dedicated to incoming links only (Csardi \& Nepusz, 2006). To compensate for the low values of Page Rank at the beginning of the outbreak, weights for input to Page Rank algorithm were modified. We upweigh each link in inverse proportion on steps of simulation (new node's attachment time in days) to evaluate agents in the early steps (more close to the sources). We call this new measurement - Adjusted Page Rank. For out- centrality, we use a negative version of Page Rank (transposed directions of the graph).

\section{RESULTS}

We have created the environment for testing our innovative risk assessment models that could increase safety of care. We had performed discussion sessions with infection control teams on organisational and medical prior parameters, we also had fitted actual parameters, so at the end we attended to validate the ability of this tool in hospital epidemiology. For evaluation of our system we test its performance in retrospective as well in the most important prospective study.

\section{RETROSPECTIVE VALIDATION STUDY}

Retrospective validation was a qualitative procedure of verifying if there is significant information in a real contact network and simulated path of infections. We examined our collected networks in comparison to social contact empirical studies like in hospitals in Lyon (Vanhems et al., 2013) and Rome (Barrat et al., 2010) as well as with other physical contacts as Polish chapter of Polymod (Grabowski \& Rosińska, 2012; Mikołajczyk et al., 2008).

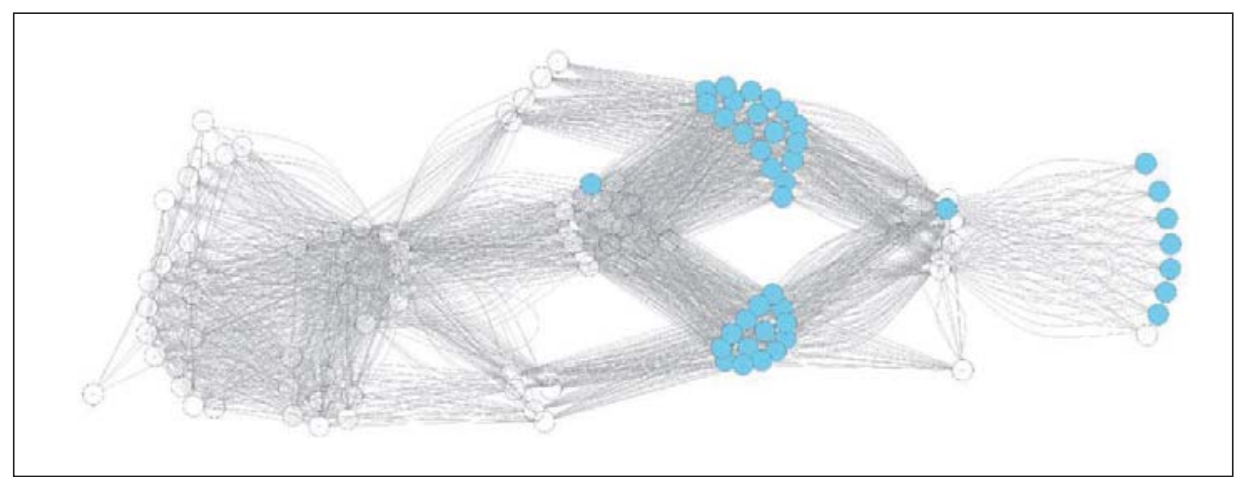

Fig. 6. A single day of a single clinic containing three wards. Personnel is coloured Source: Own research

On a given example of two week observation: network of 152 patients and 101 personnel staff we obtained: Louvain Clustering procedure revealed 3 communities, global clustering coefficient 0.6 , average path length 1.9 , mean degree 31 , median links loyalty $20 \%$. Our extractions do not vary so much with other 
hospitals or other physical contact networks from both dynamic and static perspectives.

We attempted to verify if the extracted network contains explanatory value for transmission events. To do so, we used historical outbreaks we have access to, with the number of infections greater than 2 and we shuttled the links, thus real temporal and topological structure were permuted (Rocha et al., 2020). Probability of acquiring infection if being in contact with infected according to procedure proposed in hospital study in Normand (Obadia et al., 2015) was significantly higher $(p<0.01)$ in real than perturbed network. Moreover, brokerage between two branches of outbreaks representing personnel was correctly indicated by algorithm (Fig. 5), as it was indicated in the outbreak investigation.

\section{Prospective Validation study}

Prospective study was performed during weeks 17-21.07.2017 and 12-16.11.2017 from selected wards in two different hospitals. Infection control team members inspected all patients (190) that time and assessed their risk according to their experience on the scale -3 (very low risk),-2,-1,0 (average risk),1,2,3 (very high risk) for a chance of acquiring infections. Within those 190 patients, only 35 patients have been assessed for risk of infecting others (out). Normality of in-risk humant assessment was satisfied, so we will use Pearson correlation. Agreement between system's risk assessment (in underlying contact network as well process path dimensions) and personnel's assessment was given in the table (Table 1).

Table 1

Pearson Correlation coefficients of algorithmic risk measurements (centralities) against human assessment for infection in/out risk.

\begin{tabular}{llll}
\hline Observation & network type & risk in (correlation) & risk out (correlation) \\
betweenness & contacts & $0.30^{* *}$ & 0.63 \\
betweenness & paths & 0.02 & -0.64 \\
closeness & paths & $0.20^{*}$ & -0.15 \\
eigenvector & paths & $0.19^{*}$ & -0.18 \\
PageRank (in/out) & paths & $0.35^{* *}$ & 0.30 \\
adjusted PageRank (in/out) & paths & $0.42^{* *}$ & 0.39 \\
\hline
\end{tabular}

Note ${ }^{* *}$ Statistically significant correlation $(p<0.01),{ }^{*}(p<0.05)$

Source: Own research

Correlations for out risk measurements were not significant mainly due to the small number of cases for personnel's risk-out assessment. For in-risk assessment, as we expected, Adjusted Page Rank centrality of paths reflects the best human perception of risk (correlation 0.42). The simple network of contacts reasonably well explains the risk (correlation 0.3 ) with betweenness centrality (Kitsak et al., 2010). However, the same betweenness centrality measurement does not work with simulated paths and loose even with eigenvector or closeness centralities. 


\section{Discussion}

Infectious disease informatics (epidemiological intelligence) is an already established scientific field, but still underrepresented in Poland. Control of infectious diseases in hospitals has been one of chief roles of public health to date and there are many challenges successfully solved by mathematical modelling globally (Jarynowski \& Grabowski, 2015). We developed a preliminary verified functional system in the form of a free application for automatic risk assessment. It focuses on hospital networks and specifically on the impact of co-location networks on the spread of hospital-associated pathogens. Contact networks in hospitals can be obtained with many methods and most of them can be classified into:

- hierarchical organisation studies (Ueno \& Masuda, 2008);

- empirical cohabiting studies (Jarynowski \& Liljeros, 2015);

- empirical sensor studies (Obadia et al., 2015).

Only organisational or only empirical interactions were previously modelled by many researchers, however, an integrative framework combining these approaches in order to study the spatial and temporal dynamics of disease spread was missing until our project. With simulated infection paths, we are able to compute network measures for patients. We can obtain the risk of getting infected, based on the patient's incoming connections, and the risk of spreading infections resulting from outgoing connections, both from network centrality measures (Kitsak et al., 2010). The results of the algorithms can be presented 'real-time' to a hospital epidemiologist for interpretation and applying preventive control by assigning places and individuals into different risk groups. We indicate the best one which is the Adjusted Rage Rank algorithm (Table 1). However, surprisingly good predictive power for risk assessment was found in betweenness centrality of the underlying network of contact. It can mean that specific epidemiology of a given pathogen in a given place and time could be reduced only to contact networks. Moreover at least two European projects have been assessing only contact networks (Health-i-care, 2017; EmerGe-Net, 2017), so modelling the spreading process is not as important as understanding the network behind it.

\section{LIMITATIONS}

Models attached to our software can be more or less useful, but the operational aim of modelling for hospital infections is to advise infection control teams in their work. The final aim of our computational software was providing meaningful analysis and calculations to support decisions of great importance for the hospital epidemiology, but we are not yet there. In the future our system could be an effective tool in the fight against infectious diseases.

The main limitation of our study was having no outbreak in prospective study. Accuracy measured in prospective study was better than in similar projects (however it is difficult to compare studies with different epidemiological situations and 
data availability). We still do not know how our algorithm will cope with 'realtime' projection during an ongoing outbreak, because we analysed such scenarios only retrospectively as no outbreak happened during our prospective study. Even though the utility of using our system is moderate at this moment, we put a strong focus on problem based learning of transmission patterns and evaluating disease interventions. This was an introduction to healthcare workers to digital epidemiology and modelling supporting decisions in infection control (de Bruin et al., 2014). Unfortunately, our solution is offline and most of the data must be imput by hand. Cloud service and automatic data collections from HIS would increase usability of such a system (Czekaj et al., 2021; Vitabile et al., 2019).

As most of the modeling literature concentrates on MRSA, our software is also primarily adjusted to this pathogen (Rocha et al., 2020). However, current epidemiological trends in Poland showing emergence of Carbapenem-resistant enterobacteriaceae (Deptuła, et al., 2015), Clostridium Difficile (SadkowskaTodys, Zieliński \& Czarkowski, 2017) and Acinetobater Baumani (Jarynowski, Marchewka \& Grabowski, 2017), and we also try to adjust our model to the newest situation. Thus, further model improvement should assess mentioned pathogens, because their transmission dynamics translated to mathematical modelling is still not satisfactory described.

\section{Conclusion and Future Plans}

Powerful computer facilities and ubiquitous GPS and bluetooth devices have made possible the collection, processing and storage of the data on individual persons (Belik, Geisel \& Brockmann, 2011), especially in a total institution such as a hospital. With using electronic logins for staff and patients or beacons in future, we could skip heuristic techniques for model parameterisation for each place and each healthcare, so it would solve problems with current staff computationally tractable. In addition to obtaining numerical risk indicators, the infection control team is mapping the infection ecosystem in their hospital. Expanded knowledge about the structure of contacts gained with SIRSZ system may be translated into the epidemiological safety of patients. COVID-19 pandemic changed the organisational behaviour of the health care staff to cluster contacts and avoid bridging infection between wards as it was shown on Figure 5, where a staff member was identified as an infection transmitter from one to another location in hospital. Moreover, mobile phone apps and beacons (mainly bluetooth badges) have been applied in monitoring people outside of hospitals setting in COVID-19 contact tracing context (Kontakt, 2020). We believe that the implementation and future development of the ICT solutions implemented during the COVID-19 pandemic will allow for better risk assessment, and this will translate into the safety of hospitalized patients.

Personalization and Phylogenetic outbreak investigation

With Patient Electronic Medical Record data providing reasonably accurate information on procedures and comorbidities (Furuya-Kanamori et al., 2017), additional layer of risk assessment could be build as it was partly done for Cesar- 
ean Section Surgical Site Infection (Różańska et al., 2018) in other branch of the our System SIRSZ. We are planning to integrate risk assessment for a given patient due to network position with risk assessment due to procedures and comorbidities.

Using genetic pathogens relationships through phylogenetic inference methods could also help in evaluation of observed transmission paths. We can take a group of genomes of isolates from patients and construct phylogenetic trees on the basis of sequence variation in different genes as single nucleotide polymorphisms (SNPs) (Sadsad et al., 2016). In future, genomic trees should be combined with epidemiological data for a better prediction.

Acknowledgments. Most of all, the tools with instruction used in these projects are publicly available both in Polish and English with free license on http:/ / platforma.sirsz.pl. Moreover codes and algorithms are also open-sourced on http://platforma.sirsz.pl and on additional repositories http://github.com/ sirsz/Elpis. Project was fully financed by NCBiR Social Innovation II schema (IS2/195/NCBR/2015) and we thank involved project partners Damian Marchewka, Sebastian Kupny, Andrzej Grabowski.

\section{REFERENCES}

[1] Adlassnig, K-P., et al. (2012). Artificial-Intelligence-Based Hospital-Acquired Infection Control digitalized data concerning the patient's medical history, In R.G. Bushko (Ed.), Strategy for the Future of Health (pp. 103-110). IOS Press.

[2] Ahmed, N., et al. (2020). A survey of COVID-19 contact tracing apps. IEEE access, 8, 134577-134601. http:/ / doi.org/10.1109/ ACCESS.2020.3010226

[3] Barrat, A., Cattuto, C., Colizza, V., Isella, L., Rizzo, C., Tozzi, A.E. \& Van den Broeck, W. (2010). Wearable sensor networks for measuring face-to-face contact patterns in healthcare settings. In International Conference on Electronic Healthcare (pp. 192-195). Springer. http://doi.org/10.1007/978-3-642-23635-8_24

[4] Becker, A. D., Grantz, K. H., Hegde, S. T., Bérubé, S., Cummings, D. A., \& Wesolowski, A. (2021). Development and dissemination of infectious disease dynamic transmission models during the COVID-19 pandemic: what can we learn from other pathogens and how can we move forward?, The Lancet Digital Health, 3(1), e41-e50. http://doi. org/10.1016/S2589-7500(20)30268-5

[5] Belik, V., Geisel T., \& Brockmann, D. (2011). Natural human mobility patterns and spatial spread of infectious diseases, Physical Review X, 1(1), 011001. https://doi. org/10.1103/PhysRevX.1.011001

[6] Belik, V., Hovel P., \& Mikolajczyk R. (2016). Control of Epidemics on Hospital Networks. In Control of Self-Organizing Nonlinear Systems (pp. 431-440). Springer. https:/ / doi.org/10.1007/978-3-319-28028-8_22

[7] Belik, V., Karch, A., Hövel, P., \& Mikolajczyk, R. (2017). Leveraging Topological and Temporal Structure of Hospital Referral Networks for Epidemic Control. In Temporal Network Epidemiology (pp. 199-214). Springer. https:/ / doi.org/10.1007/978-981-10-5287-3_9

[8] Cassini, A., et al. (2016). Burden of six Healthcare-associated infections on european population health: estimating incidence-based disability-adjusted life years through a population prevalence-based modelling study. PLoS medicine, 13(10), e1002150. 
https:/ / doi.org/10.1371/journal.pmed.1002150

[9] Csardi, G., \& Nepusz, T. (2006). The igraph software package for complex network research. International Journal of Complex Systems, 1695(5), 1-9.

[10] Curtis, D. E., Hlady, C. S., Pemmaraju, S.V., Polgreen, P. M., \& Segre, A. M. (2010). Modeling and estimating the spatial distribution of healthcare workers. In Proceedings of the 1st ACM International Health Informatics Symposium, (pp. 287-296). ACM. https:/ / doi.org/10.1145/1882992.1883034

[11] Czekaj, Ł., Domaszewicz, J., Jarynowski, A., Kitłowski, R. \& Doboszyńska, A. (2021). Validation and usability of AIDMED - telemedical system for cardiological and pulmonary disease. [Manuscript accepted for publication in e-methodology]

[12] de Bruin, J.S., Seeling, W., \& Schuh, C. (2014). Data use and effectiveness in electronic surveillance of healthcare associated infections in the 21st century: a systematic review. Journal of the American Medical Informatics Association, 21(5), 942-951. https://doi. org/10.1136/amiajnl-2013-002089

[13] Deptuła, A., Trejnowska, E., Ozorowski, T., \& Hryniewicz, W. (2015). Risk factors for healthcare-associated infection in light of two years of experience with the ECDC point prevalence survey of healthcare-associated infection and antimicrobial use in Poland. Journal of Hospital Infection, 90(4), 310-315. https:/ / doi.org/10.1016/j.jhin.2015.03.005

[14] Donker, T., Wallinga, K., \& Grundmann, H. (2010). Patient referral patterns and the spread of hospital-acquired infections through national health care networks. PLoS Comput Biol, 6(3); e1000715. https:// doi.org/10.1371/journal.pcbi.1000715

[15] Donker, T., et al. (2021). Navigating hospitals safely through the COVID-19 epidemic tide: predicting case load for adjusting bed capacity. Infection Control $\mathcal{E}$ Hospital Epidemiology, 42(6), 653-658. https:/ / doi.org/10.1017/ice.2020.464

[16] ECDC. (2020). Contact tracing: Public health management of persons, including healthcare workers, having had contact with COVID-19 cases in the European Union-second update.

[17] Eggo, R.M., Cauchemez, S., \& Ferguson, N.M. (2011). Spatial dynamics of the 1918 influenza pandemic in England, Wales and the United States. Journal of The Royal Society Interface, 8(55), 233-243. https:/ / doi.org/10.1017/10.1098/rsif.2010.0216

[18] EMerGe-Net. (2017). Effectiveness of infection control strategies against intra- and interhospital transmission of MultidruG-resistant Enterobacteriaceae. Retrieved August 21, 2021, from https:/ / www.medizin.uni-halle.de/index.php?id=7761.

[19] Furuya-Kanamori, L., Doi SA., Smith, P.N., Bagheri, N., Clements, A.C., \& Sedrakyan A. (2017). Hospital effect on infections after four major surgical procedures: outlier and volume and outcome analysis using all-inclusive state data. Journal of Hospital Infection. 97(2), 115-121. https:/ / doi.org/10.1016/j.jhin.2017.05.021

[20] Grabowski, A., \& Rosińska, M. (2012). The relationship between human behavior and the process of epidemic spreading in a real social network. The European Physical Journal B, 85(7), 248. https://doi.org/10.1140/epjb/e2012-20250-1

[21] Grabowski A., \& Jarynowski, A. (2016). Rumor propagation in temporal contact network from Polish polls, In 2016 Third European Network Intelligence Conference (ENIC) (pp. 85-89). IEEE. https://doi.org/10.1109/ENIC.2016.020

[22] Grabska, E., Łachwa, A., \& Ślusarczyk, G. (2012). New visual languages supporting design of multi-storey buildings. Advanced Engineering Informatics, 26(4), 681-690.

[23] Grundmann H., \& Hellriegel B. (2006). Mathematical modelling: a tool for hospital infection control. The Lancet infectious diseases, 6(1), 39-45. https://doi.org/10.1016/j. aei.2012.03.009

[24] health-i-care. (2017). Innovations for safer healthcare. Retrieved August 30, 2019, from http:/ / www.health-i-care.eu. 
[25] Heslop D. J., Chughtai A. A., Bui C. M., \& MacIntyre C. R. (2017). Publicly available software tools for decision-makers during an emergent epidemic-Systematic evaluation of utility and usability. Epidemics, 12, 1-2. https:// doi.org/10.1016/j.epidem.2017.04.002

[26] Jaramillo C., Taboada M., Epelde F., Rexachs D., \& Luque E. (2015). Agent based model and simulation of MRSA transmission in emergency departments. Procedia Computer Science, 51, 443-452. https:// doi.org/10.1016/j.procs.2015.05.267

[27] Jarynowski, A. (2014). Obliczeniowe Nauki Społeczne w Praktyce. Wydawnictwo Niezależne.

[28] Jarynowski, A., \& Liljeros, F. (2015). Contact networks and the spread of MRSA in Stockholm hospitals. In Second European Network Intelligence Conference (ENIC), (pp. 150-154), IEEE. https:// doi.org/10.1109/ENIC.2015.30.

[29] Jarynowski, A., \& Grabowski, A. (2015). Modelowanie epidemiologiczne dedykowane Polsce [Mathematical modelling dedicated to Poland], "Portal CZM" (Centrum Zastosowań Matematyki), ISBN 978-83-942807-9-6

[30] Jarynowski, A., Marchewka, D., \& Grabowski, A. (2017). SIRSZ: System Informatyczny Redukcji Szpitalnych Zakażeń Raport z Badania. IBI.

[31] Jarynowski, A. \& Grabowski, A. (2018). Influence of Temporal Aspects and AgeCorrelations on the Process of Opinion Formation Based on Polish Contact Survey. In International Conference on Social Informatics (pp. 118-128). Springer. https://doi. org/10.1007/978-3-030-01159-8_11

[32] Jarynowski, A., Marchewka, D., \& Buda A. (2018). Internet-assisted risk assessment of infectious diseases in women sexual and reproductive health. E-methodology, 4, 135144. https://doi.org/

[33] Jarynowski, A. \& Grabowski, A. (2019). Niewykorzystany potencjał systemów informatycznych w epidemiologii zakażeń szpitalnych w Polsce. Collegium of Economic Analysis Annals, 56, 261-273.

[34] Kontakt. (2020). Introducing Enterprise 'COVID-19 Contact Tracer' Webapp to Prevent Infections Spread in Corporate. Retrieved August 21, 2021, from https://kontakt.io/ blog/introducing-enterprise-covid-19-contact-tracer-webapp-to-prevent-infectionsspread-in-corporate-real-estate/

[35] Kitsak, M., Gallos, L.K., Havlin, S., Liljeros, F., Muchnik, L., Stanley, H.E., \& Makse, H.A. (2010). Identification of influential spreaders in complex networks. Nature physics; 6(11), 888. https://doi.org/10.1038/nphys1746

[36] Knight, G. M., Davies, N. G., Colijn, C., Coll, F., Donker, T., Gifford, D. R., ... \& Atkins, K. E. (2019). Mathematical modelling for antibiotic resistance control policy: do we know enough?. BMC infectious diseases, 19(1), 1-9. https:/ / doi.org/10.1186/s12879-019-4630-y

[37] Landherr, A., Bettina, F., \& Heidemann, J. (2010). A critical review of centrality measures in social networks. Business and Information Systems Engineering, 2(6), 371-385. https://doi.org/10.1007/s12599-010-0127-3

[38] Leibovici, L., Kariv, G., \& Paul, M. (2013). Long-term survival in patients included in a randomized controlled trial of TREAT, a decision support system for antibiotic treatment. Journal of Antimicrobial Chemotherapy, 68(11), 2664-2666. https://doi. org/10.1093/jac/dkt222

[39] Lenz, H, et al. (2016). Disease spread through animal movements: a static and temporal network analysis of pig trade in Germany. PloS one, 11(5), e0155196. https:/ / doi.org/ doi: 10.1371/journal.pone.0155196

[40] Liljeros, F., Giesecke, L., \& Holme, P. (2007). The contact network of inpatients in a regional healthcare system. A longitudinal case study. Mathematical Population Studies, 14(4), 269-284. https:// doi.org/10.1080/08898480701612899 
[41] Obadia, T., et al. (2015). I-Bird Study Group. Detailed contact data and the dissemination of Staphylococcus aureus in hospitals. PLoS Comput Biol, 11(3), e1004170. https:/ / doi.org/10.1371/journal.pcbi.1004170

[42] Ohst. J., et al. (2014). The network positions of methicillin resistant Staphylococcus aureus affected units in a regional healthcare system. EPJ Data Science, 3, 1-15. https:// doi.org/10.1140/epjds/s13688-014-0029-6

[43] O'Neill, J. (2016). The review on antimicrobial resistance. Tackling drug-resistant infections globally: final report and recommendations. Welcome Trust.

[44] Paradowski, M. B., Jarynowski, A., Czopek, K., \& Jelińska, M. (2021). Peer Interactions and Second Language Learning: The Contributions of Social Network Analysis in Study Abroad versus At-Home Environments. In: R. Mitchell \& H. Tyne (Eds.), Language, Mobility and Study Abroad in the Contemporary European Context. Taylor \& Francis. https:// doi.org/10.4324/9781003087953-8

[45] Piszczek, R., Karbowski, A., Skawina, I. R., Wróbel, E., Jabłońska, Z., Kołodziej, J., \& Wróbel, M. (2021). Rola zakażeń układu moczowego ZUM w aspekcie opieki nad osobami starszymi [The role of urinary tract infections UTI in the aspect of care for the elderly]. In: J. Mesjasz \& I. Skawina (Eds.), Wspótczesne Wyzwania Gerontologii Człowiek w petni - podejście holistyczne [Contemporary Challenges of Gerontology A fully human being - a holistic approach]. SAN.

[46] Mikolajczyk, R.T., Akmatov, M. K., Rastin, S., \& Kretzschmar, M. (2008). Social contacts of school children and the transmission of respiratory-spread pathogens. Epidemiology Infection. 136(6), 813-822. https:// doi.org/10.1017/S0950268807009181

[47] Muscatello, DJ., Chughtai, AA., Heywood, A., Gardner, LJ., Heslop, DJ., Macintyre, CR. (2017). Translating real-time infectious disease modeling into routine public health practice, Emerging Infectious Diseases, 23(5), e161720. https://doi.org/10.3201/ eid2305.161720

[48] Rocha, L. E., Singh, V., Esch, M., Lenaerts, T., Liljeros, F., \& Thorson, A. (2020). Dynamic contact networks of patients and MRSA spread in hospitals. Scientific reports, 10(1), 1-10. https://doi.org/10.1038/s41598-020-66270-9

[49] Rodríguez-Rojas, A., Makarova, O., \& Rolff, J. (2014). Antimicrobials, stress and mutagenesis. PLoS pathogens, 10(10), e1004445. https://doi.org/ 10.1371/journal. ppat.1004445

[50] Różańska, A., Jarynowski, A., Kopeć-Godlewska, K., Wójkowska-Mach, J., MisiewskaKaczur, A., Lech, M., ... \& Domańska, J. (2018). Does surgical site infection after Caesarean section in Polish hospitals reflect high-quality patient care or poor postdischarge surveillance? Results from a 3-year multicenter study. American journal of infection control, 46(1), 20-25. https:/ / doi.org/10.1016/j.ajic.2017.07.025

[51] Rustam, A. H. (2006). Epidemic Network and Centrality. Masteroppgave, University of Oslo.

[52] RPL „Rządowy Proces Legislacyjny RP - Konsultacje Społeczne”. (2017). Projekt ustawy o zmianie ustawy o zapobieganiu oraz zwalczaniu zakażeń i chorób zakaźnych u ludzi [Draft act amending the act on preventing and combating infections and infectious diseases in humans ], UD90, 30.10.2017.

[53] Sadkowska-Todys, M., Zieliński, A., Czarkowski, M. P. (2017). Infectious diseases in Poland in 2015. Przegl Epidemiol, 69, 329-334.

[54] Sadsad, R., Sintchenko, V., McDonnell, GD., Gilbert, GL. (2013). Effectiveness of hospital-wide methicillin-resistant Staphylococcus aureus (MRSA) infection control policies differs by ward specialty. PloS one, 8(12), e83099. https:/ / doi.org/10.1371/journal. pone.0083099 
[55] Sadsad, R., O'Sullivan, M., Sintchenko, V., \& Gilbert, G. (2016). Genotyping and genome sequencing for hospital outbreak surveillance and investigation. Infection, Disease Health. 21(3), 128. https://doi.org/10.1016/j.idh.2016.09.054

[56] Seweryn, M. (2018). Zakażenia szpitalne w polskich placówkach. [Healthcare Associated infection in Polish hospitals]. Menedżer Zdrowia, 2018(6), 20-21.

[57] Smieszek, T., Burri, E. U., Scherzinger, R., \& Scholz, R. W. (2012). Collecting close-contact social mixing data with contact diaries: reporting errors and biases. Epidemiology Infection, 140(4), 744-52. https://doi.org/10.1017/S0950268811001130

[58] Stenhem, M, et al. (2006). Epidemiology of methicillin-resistant Staphylococcus aureus (MRSA) in Sweden 2000-2003, increasing incidence and regional differences. Bmc Infectious Diseases, 6(1), 1-7.

[59] Tahir, H., López-Cortés, L. E., Kola, A., Yahav, D., Karch, A., Xia, H., ... \& Kretzschmar, M. E. (2021). Relevance of intra-hospital patient movements for the spread of healthcare-associated infections within hospitals-a mathematical modeling study. PLoS computational biology, 17(2), e1008600. https://doi.org/10.1371/journal.pcbi.1008600

[60] Teixeira, H., Norton, P., Azevedo, A., \& Pina, M. F. (2015). Indoor geographical information system: an innovative approach to analyze health events inside a hospital. Poster at GEOMED 2015, Florence.

[61] Ueno, T., \& Masuda, N. (2008). Controlling nosocomial infection based on structure of hospital social networks. Journal of theoretical biology, 254(3), 655-666. https://doi.org/ 10.1016/j.jtbi.2008.07.001

[62] Valdano, E., Poletto, C., Giovannini, A., Palma, D., Savini, L., \& Colizza, V. (2015). Predicting epidemic risk from past temporal contact data. PLoS Comput Biol, 11(3), e1004152. https:// doi.org/10.1371/journal.pcbi.1004152

[63] Vitabile, S., et al. (2019). Medical data processing and analysis for remote health and activities monitoring. In High-Performance Modelling and Simulation for Big Data Applications (pp. 186-220). Springer. https:/ / doi.org/10.1007/978-3-030-16272-6_7

[64] Vanhems, P., et al. (2013). Estimating potential infection transmission routes in hospital wards using wearable proximity sensors. PloS one, 8(9), e73970. https://doi. org/10.1371/journal.pone.0073970

[65] Wasilewski, P. (2018). Zakażenia szpitalne-nierozwiązany problem w lecznictwie zamkniętym. [Hospital infections - unresolved problem in inpatient treatment] Kontrola Państwowa, 63(6), 75-88.

[66] WHO. (2020). Digital tools for COVID-19 contact tracing: annex: contact tracing in the context of COVID-19. World Health Organization.

[67] Wójkowska-Mach, J., et al. (2016). Zakażenia szpitalne w jednostkach opieki zdrowotnej, [Hospital infections in healthcare setup]. PZWL. 